\title{
Cross-Sectional Associations between Dietary Daily Nicotinamide Intake and Patient-Reported Outcomes in Colorectal Cancer Survivors, 2 to 10 Years Post-Diagnosis
}

\author{
Wenbo Wu ${ }^{1,2, *}$, Martijn J. L. Bours ${ }^{3,4}$, Annaleen Koole ${ }^{3,4}$, Marlou-Floor Kenkhuis ${ }^{3,4}{ }^{3}$, Simone J. P. M. Eussen ${ }^{3,5,6} \oplus^{(}$, \\ Stephanie O. Breukink ${ }^{2,4,7}{ }^{10}$, Frederik-Jan van Schooten ${ }^{1,2}$, Matty P. Weijenberg ${ }^{3,4}$ and Geja J. Hageman ${ }^{1,2}$ \\ 1 Department of Pharmacology and Toxicology, Maastricht University, 6200 MD Maastricht, The Netherlands; \\ f.vanschooten@maastrichtuniversity.nl (F.-J.v.S.); g.hageman@maastrichtuniversity.nl (G.J.H.) \\ 2 NUTRIM School for Nutrition and Translational Research in Metabolism, Maastricht University, \\ 6200 MD Maastricht, The Netherlands; s.breukink@mumc.nl \\ 3 Department of Epidemiology, Maastricht University, 6200 MD Maastricht, The Netherlands; \\ m.bours@maastrichtuniversity.nl (M.J.L.B.); annaleen.koole@maastrichtuniversity.nl (A.K.); \\ m.kenkhuis@maastrichtuniversity.nl (M.-F.K.); simone.eussen@maastrichtuniversity.nl (S.J.P.M.E.); \\ mp.weijenberg@maastrichtuniversity.nl (M.P.W.) \\ 4 GROW School for Oncology and Developmental Biology, Maastricht University, \\ 6200 MD Maastricht, The Netherlands \\ 5 CARIM School for Cardiovascular Diseases, Maastricht University, 6200 MD Maastricht, The Netherlands \\ 6 CAPHRI School for Care and Public Health Research Institute, Maastricht University, \\ 6200 MD Maastricht, The Netherlands \\ check for \\ updates \\ 7 Department of Surgery, Maastricht University Medical Centre+, 6200 MD Maastricht, The Netherlands \\ * Correspondence: w.wu@maastrichtuniversity.nl
}

Citation: $\mathrm{Wu}, \mathrm{W} . ;$ Koole, A.; Kenkhuis, M.-F.; Eussen, S.J.P.M.; Breukink, S.O.; van Schooten, F.-J.; Weijenberg, M.P.; Hageman, G.J. Cross-Sectional Associations between Dietary Daily Nicotinamide Intake and Patient-Reported Outcomes in Colorectal Cancer Survivors, 2 to 10 Years Post-Diagnosis. Nutrients 2021, 13, 3707. https://doi.org/ 10.3390/nu13113707

Received: 7 September 2021

Accepted: 20 October 2021

Published: 21 October 2021

Publisher's Note: MDPI stays neutral with regard to jurisdictional claims in published maps and institutional affiliations.

Copyright: (c) 2021 by the authors. Licensee MDPI, Basel, Switzerland. This article is an open access article distributed under the terms and conditions of the Creative Commons Attribution (CC BY) license (https:// creativecommons.org/licenses/by/ $4.0 /)$.
Abstract: Supplementation with nicotinamide adenine dinucleotide $\left(\mathrm{NAD}^{+}\right)$precursors including dietary nicotinamide has been found to boost tissue $\mathrm{NAD}^{+}$levels and ameliorate oxidative stressinduced damage that contributes to aging and aging-related diseases. The association between dietary $\mathrm{NAD}^{+}$precursors and patient-reported health-related outcomes in cancer survivors has not been investigated. This study aimed to determine associations of dietary nicotinamide intake with different patient-reported outcomes in colorectal cancer survivors, 2 to 10 years post-diagnosis. A total of 145 eligible participants were recruited into this cross-sectional study. Dietary nicotinamide intake level was calculated based on data from 7-day food diaries. Fatigue was assessed with the Checklist Individual Strength (CIS), which is a subscale of the cancer-specific European Organization for the Research and Treatment of Cancer Quality of Life Questionnaire-Core 30 (EORTC), and anxiety and depression were assessed with Hospital Anxiety and Depression Scale (HADS). Oxidative stress marker serum protein carbonyl contents and serum $\mathrm{NAD}^{+}$levels were measured. A hierarchical linear regression model with confounder adjustment was performed to analyze the association of nicotinamide intake, serum protein carbonyl contents, and $\mathrm{NAD}^{+}$levels with patient-reported outcomes. The median values of daily nicotinamide intake for male and female participants were 19.1 and $14.4 \mathrm{mg}$, respectively. Daily dietary nicotinamide intake was associated with a lower level of fatigue $(\beta$ : $-14.85(-28.14,-1.56))$ and a lower level of anxiety and depression $(\beta:-4.69(-8.55,-0.83))$. Subgroup analyses by sex showed that a beneficial association between nicotinamide intake and patient-reported outcomes was mainly found in men. To conclude, our findings suggested that higher dietary $\mathrm{NAD}^{+}$precursor nicotinamide intake was cross-sectionally associated with less patient-reported outcomes in CRC survivors.

Keywords: colorectal cancer survivor; fatigue; patient-reported outcomes; nicotinamide; $\mathrm{NAD}^{+}$precursor

\section{Introduction}

Colorectal cancer $(\mathrm{CRC})$ is the third-most common cancer worldwide in men and women combined [1]. The incidence of CRC is expected to rise up to 2.2 million new cases 
per year by 2030 [2]. Increased aging of the population, unfavorable dietary habits, and specific risk factors (e.g., overweight, physical inactivity and sedentary behavior, alcohol consumption, smoking, and comorbidities such as inflammatory bowel disease and type II diabetes mellitus) have been reported to account for this trend in CRC incidence [3]. At the same time, early detection and improved treatments have improved the CRC survival rates in recent decades [4]. CRC survivors often report various complaints or adverse effects after treatment, such as fatigue, pain, impaired sleep, and mental problems, which may affect health-related quality of life (HRQoL) [5]. Thus, identifying targets and factors for interventions to promote better HRQoL of CRC survivors is warranted.

As mentioned, aging is a critical factor contributing to the growing population of CRC survivors. Aging is marked by a systemic decrease in nicotinamide adenine dinucleotide $\left(\mathrm{NAD}^{+}\right)$across multiple tissues [6]. NAD ${ }^{+}$declines have been linked with aging and agingrelated disorders, including age-associated metabolic disorders, cancer, neurodegenerative diseases, and mental disorders $[7,8]$. $\mathrm{NAD}^{+}$is a co-enzyme involved in cellular metabolism and has a regulating role in various biological processes. Its biosynthesis and turnover have recently been attracting more interest $[7,9]$. When the activities of $\mathrm{NAD}^{+}$-dependent enzymes, such as CD38/157 and poly (ADP-ribose) polymerase-1 (PARP-1) are chronically increased, specifically under chronic inflammation and oxidative stress, this may lead to $\mathrm{NAD}^{+}$decline and a reduced substrate availability for sirtuins that are involved in antiaging signaling [8]. Supplementation with small molecular compounds used for $\mathrm{NAD}^{+}$ biosynthesis, so-called $\mathrm{NAD}^{+}$precursors, such as nicotinamide riboside (NR), nicotinamide mononucleotide (NMN), and nicotinamide (NA), has been found to exert preventive and therapeutic effects that ameliorated aging-associated pathophysiologies in animal models [10-13]. These emerging findings have brought a promising intervention, a socalled "NAD" boosting" strategy. A recent study showed that supplementing patients with niacin (nicotinic acid), a dietary $\mathrm{NAD}^{+}$precursor, indeed ameliorated $\mathrm{NAD}^{+}$deficiency and improved muscle performance in patients with adult-onset mitochondrial myopathy [14].

CRC survivors frequently report fatigue, depression, and anxiety, and yet the underlying mechanisms remain elusive. Cancer treatment, especially chemotherapy and radiotherapy, have previously been found to be associated with impaired health outcomes [15]. Inflammation and oxidative stress triggered by chemotherapeutic agents can be a double-edged sword. On the one hand, when inducing treatment response against tumor cells, it can also impair normal cells. On the other hand, chemotherapeutic agents can induce cell senescence, which could lead to a senescence-associated secretory phenotype (SASP), a complex panel of excreted factors that may bring chronic systemic inflammation and contribute to increased $\mathrm{NAD}^{+}$consumption [16]. Evidence for an ameliorating effect of a NAD ${ }^{+}$boosting strategy was obtained in a recent animal study. When a diet supplemented with nicotinamide, a form of Vitamin B3 and the most common $\mathrm{NAD}^{+}$ precursor, was fed to mice, it was found to reduce oxidative stress and inflammation, maintain $\mathrm{NAD}^{+}$levels, and improve health [13]. Even though nicotinamide-rich foods are widely available and nicotinamide intake in the general Dutch population is generally meeting the requirements [17], chronic inflammation occurs in CRC survivors $[8,18,19]$ and may contribute to an increased degradation of $\mathrm{NAD}^{+}$, resulting in a disruption of $\mathrm{NAD}^{+}$ homeostasis. However, whether and how a disturbed $\mathrm{NAD}^{+}$homeostasis may be related to patient-reported outcomes in CRC survivors has not been investigated. Therefore, in this cross-sectional study with CRC survivors 2 to 10 years after diagnosis, we aimed to investigate how dietary nicotinamide intake, serum $\mathrm{NAD}^{+}$concentration (as a marker of $\mathrm{NAD}^{+}$status), and protein carbonyl contents (as a marker for oxidative stress) are associated with hand-grip strength and patient-reported outcomes including emotional and cognitive functioning, fatigue, depression, and anxiety. 


\section{Materials and Methods}

\subsection{Study Design and Population}

Data from the "Energy for Life after ColoRectal Cancer" (EnCoRe) study were used, which has been described previously [20]. The EnCoRe study includes an ongoing prospective part and a cross-sectional part. Data from the cross-sectional part were used for the present analyses. Basically, the cross-sectional study included CRC survivors 2 to 10 years after diagnosis of stage I to III CRC. Eligible participants who were diagnosed and treated between 2002 and 2010 at Maastricht University Medical Center+, the Netherlands, were recruited into the study between 2012 and 2013. An overview of patient recruitment including reasons for exclusion is given in Figure 1; in total, 145 subjects were eligible for the current study. The EnCoRe study has been approved by the Medical Ethics Committee of the Academic Hospital Maastricht and Maastricht University, the Netherlands (Project identification code: METC 11-3-075). Informed consent was signed by all participants.

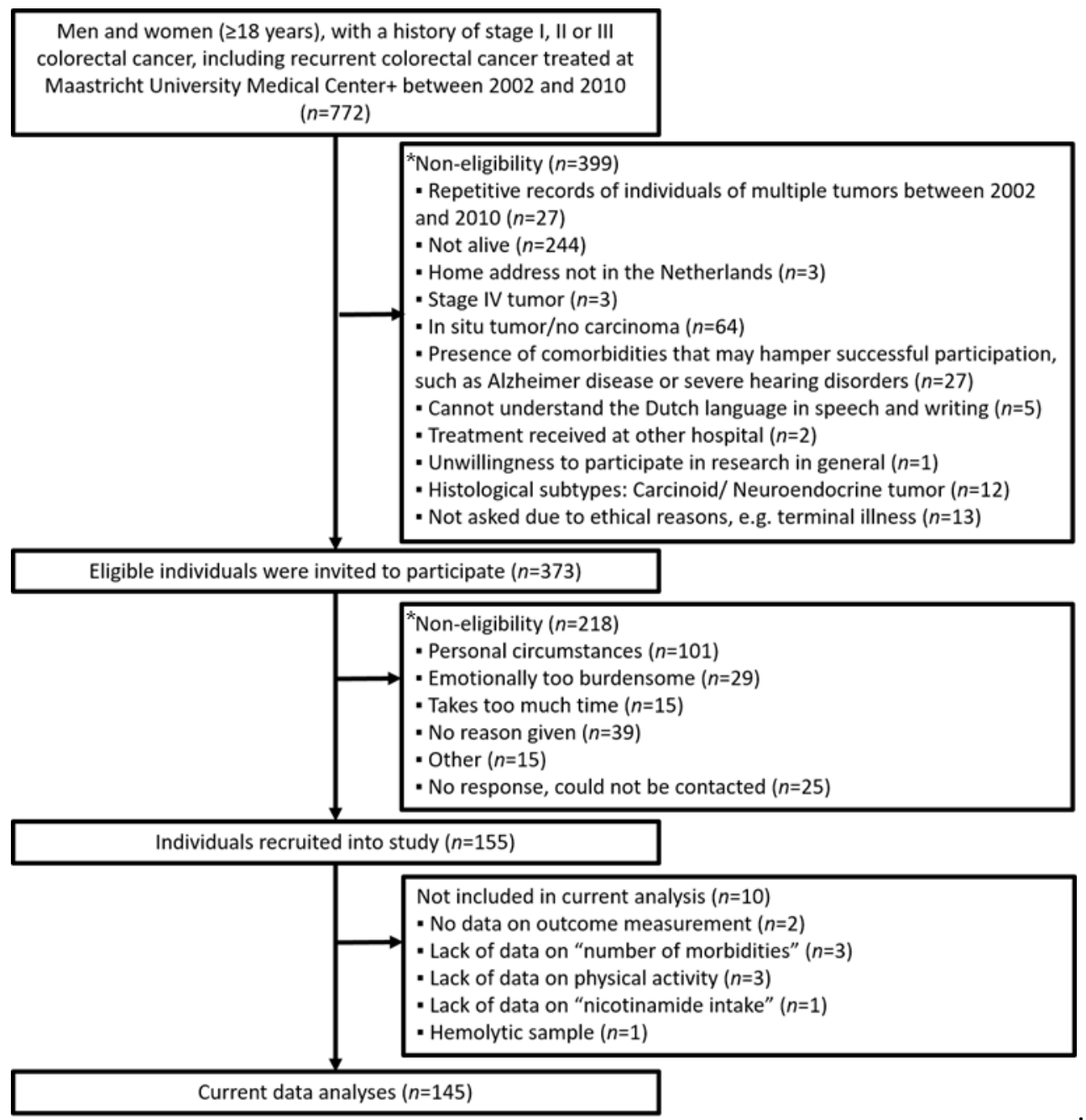

Figure 1. Flow diagram of individuals included in the cross-sectional part of the EnCoRe study $(*$ : some participants may have multiple reasons).

\subsection{Calculation of Average Daily Nicotinamide Intake}

A seven-day dietary record was obtained from each participant to quantitatively estimate food intake. All subjects received detailed written and oral instructions during a home visit for determining the type and amount of food to be recorded. The dietary record contained three standard mealtimes (breakfast, lunch, and dinner) and any snack moments in between. Participants were requested to provide a sufficient amount of detail, 
such as the brand names of consumed foods, ingredients used, quantified food intake (using either grams or standardized household measures, i.e., tablespoon, glass, etc.), cooking methods (e.g., boiled, in oven, or marinade), and recipes (including ingredients for ready-to-serve meals). Upon receipt of completed dietary records, a quality control check for consistency and completeness was conducted afterwards by the researchers. In case of any inconsistencies or missing information, participants were contacted for additional information. Next, dietary records were coded by trained dieticians based on the Dutch Food Composition Database 2011 (NEVO), which contains energy and macro- and micro-nutrient values for each food and drink. More details were given previously [21-23]. Average daily nicotinamide intake was calculated in milligrams per day by multiplying food frequencies and dosage. In addition to the dietary records, information on the use of dietary supplements was collected according to the procedures described previously [22] Briefly, participants were asked to report whether one or more supplement was used, the start and stop date, the ingredients, and the motivations for use. Each participant was also asked to provide the original package of the supplements if available.

\subsection{Measurement of Serum Protein Carbonyl Contents and $N A D^{+}$Levels}

A venous blood sample was drawn from study participants during a home visit. Blood samples were collected in $8.5 \mathrm{~mL}$ serum tubes (BD Vacutainer SST II Advance), and after centrifugation, aliquots were cryopreserved at $-80{ }^{\circ} \mathrm{C}$ within $4 \mathrm{~h}$ after blood drawing until analysis. Serum concentrations of protein carbonyl products were measured based on 2,4-dinitrophenylhydrazine (DNPH) colorimetric assay [24]. The concentration of protein carbonyl products was normalized using the total protein concentration of serum, which was determined with the Bradford assay. Serum NAD ${ }^{+}$levels were determined spectrophotometrically using the thiazolyl blue cycling assay established by Bernofsky and Swan [25]. Briefly, each assay contained $100 \mathrm{mM}$ bicine, pH 7.8; $500 \mathrm{mM}$ ethanol; $0.42 \mathrm{mM}$ 3-[-4,5-dimethylthiazol-2-yl]-2,5-diphenyl tetrazolium bromide (MTT); $1.66 \mathrm{mM}$ phenazine methosulfate (PMS); and 14 units alcohol dehydrogenase (ADH). The amounts of $\mathrm{NAD}^{+}$were measured as the change in absorbance at $590 \mathrm{~nm}$ at $37^{\circ} \mathrm{C}$ for $10 \mathrm{~min}$ with a Model 680XR microplate reader (BioRad, Hercules). In case of potential contamination of erythrocytes caused by blood drawing, a quality control procedure by measuring serum free hemoglobin levels (fHB) determined by 3,3',5,5'-tetramethylbenzidine (TMB) assay was also carried out [26]. The cut-off value for hemolytic samples was set on $\mathrm{fHB} \geq 1.4 \mathrm{mg} / \mathrm{mL}[27,28]$. The hemoglobin concentrations presented in the serum sample were relatively low (below $0.059 \mathrm{mg} / \mathrm{mL}$ ), indicating that the contamination of potential erythrocytes during sample collecting can be negligible. Quality control (QC) samples were introduced, and both study and QC samples were analyzed in triplicate. Coefficient of variation $(\mathrm{CV})$ within (inter-assay $\mathrm{CV}$ ) and between different runs (intra-assay $\mathrm{CV}$ ) were calculated, and both the inter and intra-assay CV for the measurements were below $10 \%$.

\subsection{Outcome Measurement}

Fatigue was measured by the Checklist Individual Strength (CIS), which is a 20-item questionnaire measuring complaints of fatigue on a 7-point Likert scale. The CIS contains four subscales on separate dimensions of fatigue, i.e., subjective feelings of fatigue (scores ranging from 8 to 56), concentration problems (scores ranging from 5 to 35), reduced motivation (scores ranging from 4 to 28), and reduced physical activity (scores ranging from 3 to 21). Then, scores of individual CIS subscales were summed to a total score for fatigue, ranging from 20 to 140 [29-32]. Higher scores indicate more severe levels of fatigue.

The 14-item Hospital Anxiety and Depression Scale (HADS) was used to assess levels of psychological distress (scores ranging from 0 to 42), including an anxiety and a depression subscale. Scoring for each item ranges from zero to three, with three denoting highest anxiety or depression level. Fatigue, emotional, and cognitive functioning were addressed by specific subscales of the cancer-specific European Organization for the Research and Treatment of Cancer Quality of Life Questionnaire-Core 30 (EORTC QLQ-C30, 
version 3.0) [31]. Item scores were each converted to a scale ranging from 0 to 100 , with higher scale scores representing more fatigue or better functioning.

Dominant hand maximum isometric hand-grip strength, representing muscle function, was measured with a Jamar hand dynamometer (Sammons Preston Rolyan, Bolingbrook, IL, US). Two measurements were conducted per participant, of which the highest value was used as maximum hand-grip strength [31].

\subsection{Other Factors}

Information on demographic factors (age, sex) and smoking status were obtained through self-report. Comorbidities were assessed by the Self-Administered Comorbidities Questionnaire [20,30]. Clinical characteristics such as date of CRC diagnosis, tumor stage, and treatment(s) received (chemotherapy, radiotherapy, and/or surgery) were obtained through the Netherlands Cancer Registry. Body height and weight, to calculate body mass index $\left(\mathrm{BMI}\right.$ in $\mathrm{kg} / \mathrm{m}^{2}$ ), were measured by trained research personnel during a home visit. The "Short QUestionnaire to ASsess Health enhancing physical activity (SQUASH)" was used to measure the level and intensity of physical activity by assessing the frequency (days per week), duration (time per day), and intensity (low, moderate, high) of different types of activities [20]. Moderate-to-vigorous physical activity (MVPA, hours/week) was regarded as all activity of more than 3 metabolic equivalents (MET) [20,33].

\subsection{Statistical Analysis}

Descriptive analysis on demographic and clinical characteristics was performed using means and standard deviations (SD) for normally distributed continuous variables or medians and interquartile ranges (IQR) for non-normally distributed variables. Frequencies and percentages were used to describe categorical variables. Due to the right-skewed distribution of nicotinamide intake, a natural-log transformation was done to obtain a normal distribution. Linear correlation between daily nicotinamide intake with natural-log transformation and the other variables (including all the biomarkers, i.e., serum $\mathrm{NAD}^{+}$ levels and protein carbonyl contents) was assessed with Pearson or Spearman correlation coefficients based on the type and distribution of variables.

To assess the relation of nicotinamide intake, serum $\mathrm{NAD}^{+}$levels, and protein carbonyl contents with the outcomes of interest, i.e., hand-grip strength, emotional and cognitive functioning, fatigue, and anxiety and depression, multivariate linear regression models with a hierarchical approach were used to estimate unstandardized regression coefficients $(\beta)$ with $95 \%$ confidence intervals (CIs). $\beta$ s represent the confounder-adjusted difference in score of the outcome per one-unit increase in the Ln-transformed value of the average daily nicotinamide intake as the independent variable. Relevant confounders that were included in all models based on evidence from the literature and biological plausibility were sex, age (years), BMI $\left(\mathrm{kg} / \mathrm{m}^{2}\right)$, daily energy intake (kcal), number of comorbidities $(0 / 1 / 2+)$, and treatment with chemotherapy (yes/no). Additionally, further potential confounders were included based on whether inclusion of the variable changed the adjusted beta-coefficient of interest by $10 \%$ or more. These additional covariates included supplement use (yes/no) and MVPA (hours/week). According to National Institutes of Health (NIH), the recommended dietary allowance (RDA) of nicotinamide intake is different between male and female adults; i.e., for male adults, it is $16 \mathrm{mg} / \mathrm{d}$, while it is $14 \mathrm{mg} / \mathrm{d}$ for female adults [34]. Therefore, stratified analysis by sex was performed, and the independent variable was dichotomized into two categories based on recommended RDA for nicotinamide (meet the RDA or not). This allows for better understanding of association between sex-specific nicotinamide intake levels and outcomes. In addition, associations between outcomes and nicotinamide intake dosage (below RDA, between 1 and 1.25 times of RDA, above 1.25 times of RDA) were analyzed to investigate a dose-response relation. The cut-off intake level used for the dose-response relation was set based on the sample numbers and were similar within each dichotomized group. The $p$ value for linearity trend was calculated by including the dichotomized groups as a continuous variable in the model. Analyses were 
performed using IBM SPSS Statistics (Version 25, IBM Corporation: Armonk, NY, USA); statistical significance was set at $p<0.05$ (two-sided).

\section{Results}

\subsection{Participant Characteristics}

A total of 145 participants were included in the present analyses (Figure 1), of which $62.8 \%$ were males (Table 1$)$. The mean $( \pm \mathrm{SD})$ age was $70.0 \pm 9.0$ years. The median (IQR) time since diagnosis was 6.0 (3.0) years, and the majority of the participants had received chemotherapy $(51.7 \%)$, radiotherapy $(37.2 \%)$, and surgery $(95.9 \%)$. The median values (IQR) of daily nicotinamide intake for male and female participants were 19.1 (7.5) and 14.4 (6.3) $\mathrm{mg}$, respectively.

Table 1. Socio-demographic and clinical characteristics of colorectal cancer survivors $(n=145)$, diagnosed with stage I-III colorectal cancer at Maastricht University Medical Center (2002-2010).

\begin{tabular}{|c|c|c|c|}
\hline & $\begin{array}{c}\text { Male } \\
(n=91)\end{array}$ & $\begin{array}{l}\text { Female } \\
(n=54)\end{array}$ & $\begin{array}{c}\text { Total Population } \\
\quad(n=145)\end{array}$ \\
\hline Age, mean (SD) & $70.0(8.0)$ & $70.0(10.0)$ & $70.0(9.0)$ \\
\hline \multicolumn{4}{|l|}{ BMI, $n(\%)$} \\
\hline$<25 \mathrm{~kg} / \mathrm{m}^{2}$ & $21(23.1)$ & $17(31.5)$ & $38(26.2)$ \\
\hline$\geq 25 \mathrm{~kg} / \mathrm{m}^{2}$ & $70(76.9)$ & $37(68.5)$ & $107(73.8)$ \\
\hline \multicolumn{4}{|l|}{ Smoking status, $n(\%)$} \\
\hline Former or never & $79(86.8)$ & $50(92.6)$ & $127(87.5)$ \\
\hline Current & $12(13.2)$ & $4(7.4)$ & $18(12.5)$ \\
\hline \multicolumn{4}{|l|}{ Number of comorbidities, $n(\%)$} \\
\hline 0 & $25(27.5)$ & $11(20.4)$ & $35(24.1)$ \\
\hline 1 & $22(24.2)$ & $12(22.2)$ & $34(23.4)$ \\
\hline$\geq 2$ & $44(48.4)$ & $31(57.4)$ & $76(52.4)$ \\
\hline \multicolumn{4}{|l|}{ Cancer stage, $n(\%)$} \\
\hline I & $23(23.5)$ & $16(29.6)$ & $49(33.8)$ \\
\hline II & $31(34.1)$ & $21(38.9)$ & $52(35.9)$ \\
\hline III & $30(33.0)$ & $17(31.5)$ & $47(32.4)$ \\
\hline \multicolumn{4}{|l|}{ Received chemotherapy, $n(\%)$} \\
\hline Yes & $48(52.7)$ & $27(50)$ & $75(51.7)$ \\
\hline \multicolumn{4}{|l|}{ Received radiotherapy, $n(\%)$} \\
\hline Yes & $41(45.1)$ & $13(24.1)$ & $54(37.2)$ \\
\hline \multicolumn{4}{|l|}{ Received surgery, $n(\%)$} \\
\hline Yes & $86(94.5)$ & $53(98.1)$ & 139 (95.9) \\
\hline Years since diagnosis, median (IQR) & $6.0(3.0)$ & $6.0(3.0)$ & $6.0(3.0)$ \\
\hline Hours per week of MVPA, median (IQR) & $9.9(12.9)$ & $7.0(8.3)$ & $8.6(10.3)$ \\
\hline \multicolumn{4}{|l|}{ Dietary intake } \\
\hline Energy (kcal/d), median (IQR) & $2157.6(494.0)$ & $1578.9(382.2)$ & $1930.4(654.0)$ \\
\hline Nicotinamide (mg/d), median (IQR) & $19.1(7.5)$ & $14.4(6.3)$ & $17.3(8.0)$ \\
\hline \multicolumn{4}{|l|}{ Supplement use (yes/no), $n(\%)$} \\
\hline Yes & $38(41.8)$ & $26(48.1)$ & $64(44.1)$ \\
\hline $\begin{array}{l}\text { Serum protein carbonyl contents } \\
\text { (nmol/mg protein), mean (SD) }\end{array}$ & $32.7(19.6)$ & 38.5 (23.3) & $34.9(21.2)$ \\
\hline $\mathrm{NAD}^{+}(\mathrm{nmol} / \mathrm{L})$, mean $(S D)$ & $1572.4(731.5)$ & $1462.6(566.4)$ & $1531.3(674.4)$ \\
\hline
\end{tabular}

Negative correlations were observed for dietary nicotinamide intake with age (Pearson $r=-0.303, p<0.05)$ and with the number of comorbidities (Spearman $r h o=-0.314, p<0.05$ ). Positive correlations were observed with MVPA (Pearson $r=0.268, p<0.05$ ), sex (Spearman $r h o=0.509, p<0.05$ ), smoking status (Spearman $r h o=0.211, p<0.05$ ), and average daily energy intake (Pearson $r=0.692, p<0.05$ ). No significant correlations were found with the other variables, including the biomarkers serum protein carbonyl contents and plasma $\mathrm{NAD}^{+}$concentrations (data are not shown). 


\subsection{Associations between Dietary Nicotinamide Intake and Patient-Reported Outcomes}

As shown in Table 2, daily nicotinamide intake was significantly associated with hand-grip strength, emotional functioning, activity, and motivation subscale of the CIS questionnaire in the univariate model and model I, while in the fully adjusted model, no significance associations were observed. In fully adjusted models, as shown in Table 2, daily nicotinamide intake was significantly and inversely associated with EORTC fatigue subscale ( $\beta$ : $-14.85,95 \% \mathrm{CI}:-28.14,-1.56)$, CIS total fatigue ( $\beta$ : $-17.52,95 \% \mathrm{CI}:-34.54$, $-0.51)$, CIS subjective fatigue ( $\beta$ : $-10.47,95 \%$ CI: $-18.70,-2.25)$, HADS total distress score ( $\beta$ : $-4.69,95 \% \mathrm{CI}:-8.55,-0.83)$, and HADS anxiety score $(\beta:-2.55,95 \% \mathrm{CI}:-4.79$, -0.32 ). A $10 \%$ higher daily dietary nicotinamide intake (per $\mathrm{mg}$ ) was associated with a score 34 points lower on the EORTC fatigue scale that ranges from 0 to 100 . No statistically significant associations were observed for daily dietary nicotinamide with the cognitive functioning and concentration subscale of the CIS questionnaire in all models.

Table 2. Associations of daily nicotinamide intake with hand-grip strength, emotional and cognitive functioning, fatigue, anxiety, and depression.

\begin{tabular}{|c|c|c|c|c|c|c|}
\hline & \multicolumn{2}{|c|}{ Univariate } & \multicolumn{2}{|c|}{ Model I a $^{a}$} & \multicolumn{2}{|c|}{ Model II $^{\mathbf{b}}$} \\
\hline & $\beta^{c}$ & $95 \%$ CI & $\beta^{c}$ & $95 \%$ CI & $\beta^{c}$ & $95 \% \mathrm{CI}$ \\
\hline Hand-grip strength & 19.13 & $14.53,23.74$ & 4.81 & $0.87,8.75$ & 2.30 & $-2.41,7.02$ \\
\hline Emotional functioning & 10.90 & $3.37,18.43$ & 11.77 & $2.53,21.01$ & 10.31 & $-0.65,21.26$ \\
\hline $\begin{array}{c}\text { Cognitive functioning } \\
\text { Fatigue }\end{array}$ & 6.63 & $-1.99,15.25$ & 6.77 & $-3.91,17.45$ & 8.04 & $-4.50,20.58$ \\
\hline According to EORTC & -17.25 & $-26.43,-8.01$ & -19.64 & $-31.03,-8.25$ & -14.85 & $-28.14,-1.56$ \\
\hline According to CIS total & -16.45 & $-28.44,-4.45$ & -19.91 & $-34.72,-5.11$ & -17.52 & $-34.54,-0.51$ \\
\hline CIS subjective fatigue & -9.47 & $-15.23,-3.70$ & -11.63 & $-18.74,-4.53$ & -10.47 & $-18.70,-2.25$ \\
\hline CIS activity & -3.19 & $-5.00,-0.24$ & -3.88 & $-6.79,-1.00$ & -2.93 & $-6.20,0.33$ \\
\hline CIS motivation & -3.19 & $-5.75,-0.63$ & -3.36 & $-6.54,-0.18$ & -2.19 & $-5.79,1.42$ \\
\hline CIS concentration & -1.28 & $-4.62,2.07$ & -0.83 & $-5.00,3.33$ & -0.86 & $-5.82,4.11$ \\
\hline HADS total (distress) & -3.13 & $-5.81,-0.45$ & -4.38 & $-7.67,-1.09$ & -4.69 & $-8.55,-0.83$ \\
\hline HADS depression & -1.17 & $-2.69,0.35$ & -2.04 & $-3.92,-0.16$ & -2.12 & $-4.32,0.07$ \\
\hline HADS anxiety & -2.11 & $-3.68,-0.55$ & -2.53 & $-4.42,-0.65$ & -2.55 & $-4.79,-0.32$ \\
\hline
\end{tabular}

${ }^{a}$ Model adjusted by age, gender, and BMI; ${ }^{b}$ Model fully adjusted by daily average energy, number of comorbidities, received chemotherapy (yes/no), hours of per week MVPA, years since diagnosis, and supplement usage (yes/no); ${ }^{\mathrm{c}}$ To interpret the beta coefficient of the regression line, since a natural log transformation was done on the independent variable, the beta coefficient indicates that a $10 \%$ increase in nicotinamide intake leads to a $2.30 \beta$ units' changes of outcomes. Significantly associations were denoted with bold.

When the daily nicotinamide intake was dichotomized according to the RDA for men and women, respectively, sex-stratified analyses showed that only the associations observed in male participants were statistically significant (Table 3). In men, nicotinamide intake above the RDA was associated with a significantly lower levels of fatigue, as assessed by both the EORTC ( $\beta$ : $-10.43,95 \% \mathrm{CI}:-20.93,-0.17)$ and CIS total $(\beta:-8.97,95 \% \mathrm{CI}$ : $-23.14,-0.20)$ questionnaires, a better emotional functioning ( $\beta$ : 11.21, 95\% CI: 1.64 , $20.79)$, and a significantly reduced level of total depression and anxiety ( $\beta$ : $-3.50,95 \% \mathrm{CI}$ : $-6.94,-0.50)$, and these significant associations were not observed in women. Significant interaction between sex and nicotinamide intake was found in emotional functioning $(P$-interaction $=0.002)$, EORTC fatigue $(P$-interaction $=0.005)$, and HADS anxiety score $(P$-interaction $=0.005)$. Significant dose-response associations were observed in emotional functioning and HADS total scores when comparing the scores of participants having high ( $>1.25$ RDA, i.e., $>20 \mathrm{mg} / \mathrm{d}$ for male participants and $>17.5 \mathrm{mg} / \mathrm{d}$ for female participants) and moderate nicotinamide intake levels (between 1 and 1.25 RDA, i.e., $16-20 \mathrm{mg} / \mathrm{d}$ for male participants and $14-17.5 \mathrm{mg} / \mathrm{d}$ for female participants), with participants having lower intake levels ( $<16 \mathrm{mg} / \mathrm{d}$ for male participants and $<14 \mathrm{mg} / \mathrm{d}$ for female participants; Figure 2 and Supplementary Table S1). 

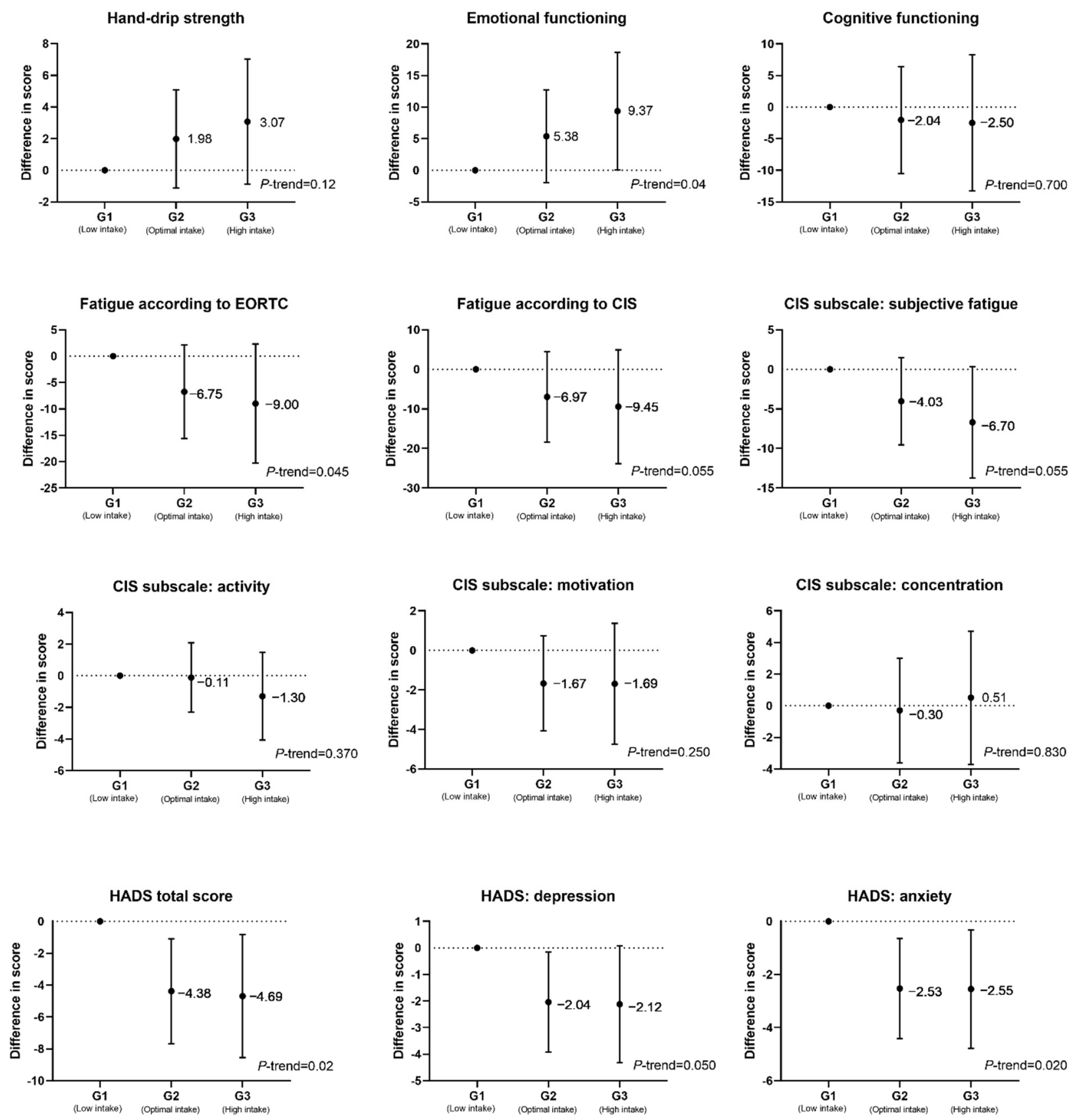

Figure 2. Dose-response relationships between daily nicotinamide intake and hand-grip strength, emotional and cognitive functioning, fatigue, anxiety, and depression. Nicotinamide intake was dichotomized into three groups, G1 (low intake level: below RDA; for male participants, it is $<16 \mathrm{mg} /$ day, while for female participants, it is $<14 \mathrm{mg} /$ day); G2 (optimal intake level: between RDA and 1.25 times RDA; for male and female participants, 16-20 mg/day and 14-17.5 mg/day, respectively); and G3 (high intake level: above 1.25 times of RDA, >20 mg/day and $17.5 \mathrm{mg} /$ day for male and female participants, respectively). Abbreviations: EORTC, European Organization for the Research and Treatment of Cancer Quality of Life Questionnaire; CIS, Checklist Individual Strength; HADS, Hospital Anxiety and Depression Scale; RDA, recommended dietary allowances.

In addition to nicotinamide intake, we also analyzed associations between the biomarkers serum $\mathrm{NAD}^{+}$levels, protein carbonyl contents, and patient-reported outcomes, but these were not associated with any of the outcome parameters (Supplementary Tables S2 and S3). 
Table 3. Results of subgroup analyses of daily nicotinamide intake dosage with hand-grip strength, emotional and cognitive functioning, fatigue, anxiety, and depression.

\begin{tabular}{|c|c|c|c|c|c|}
\hline & \multicolumn{4}{|c|}{ b G2 vs. G1 (Ref) } & \multirow{3}{*}{$P$-Interaction } \\
\hline & \multicolumn{2}{|c|}{ Male $(n=70)$} & \multicolumn{2}{|c|}{ Female $(n=29)$} & \\
\hline & $\beta$ & $95 \% \mathrm{CI}$ & $\beta$ & $95 \% \mathrm{CI}$ & \\
\hline Hand-grip strength ${ }^{a}$ & 3.35 & $-1.23,7.93$ & -0.08 & $-3.40,3.33$ & $<0.001$ \\
\hline Emotional functioning ${ }^{a}$ & 11.21 & $1.64,20.79$ & -1.42 & $-12.35,9.50$ & 0.002 \\
\hline $\begin{array}{c}\text { Cognitive functioning }{ }^{\mathrm{a}} \\
\text { Fatigue }\end{array}$ & -0.71 & $-11.19,9.77$ & -4.31 & $-18.28,9.67$ & 0.924 \\
\hline According to EORTC ${ }^{a}$ & -10.43 & $-20.93,-0.17$ & -2.60 & $-18.14,12.93$ & 0.005 \\
\hline According to CIS (total) ${ }^{a}$ & -8.97 & $-23.14,-0.20$ & -0.85 & $-20.41,18.72$ & 0.270 \\
\hline CIS subjective fatigue ${ }^{a}$ & -6.35 & $-13.57,-0.18$ & -0.73 & $-9.65,8.20$ & 0.076 \\
\hline CIS activity ${ }^{a}$ & -0.91 & $-3.67,1.85$ & 0.68 & $-2.81,4.18$ & 0.789 \\
\hline CIS motivation ${ }^{a}$ & -1.08 & $-4.18,2.03$ & -1.96 & $-5.88,1.96$ & 0.207 \\
\hline CIS concentration $^{a}$ & -1.60 & $-6.00,2.78$ & 1.75 & $-3.16,6.67$ & 0.614 \\
\hline HADS total (distress) $^{a}$ & -3.50 & $-6.94,-0.50$ & -2.08 & $-5.60,1.45$ & 0.050 \\
\hline HADS depression ${ }^{a}$ & -1.57 & $-3.61,0.48$ & -0.82 & $-2.60,0.96$ & 0.579 \\
\hline HADS anxiety ${ }^{a}$ & -2.31 & $-4.31,-0.30$ & -1.14 & $-3.35,1.07$ & 0.005 \\
\hline
\end{tabular}

$\overline{{ }^{a}}$ Model fully adjusted by age, BMI, daily average energy, number of comorbidities, received chemotherapy (yes/no), hours of per week MVPA, years since diagnosis and supplement usage (yes/no); ${ }^{b}$ Daily dietary nicotinamide intake were dichotomized into two groups, G1 ( $\leq 14 \mathrm{mg} / \mathrm{d}$ for female, $n=25, \leq 16 \mathrm{mg} / \mathrm{d}$ for male, $n=21$; as reference), G2 (>14 mg/d for female and $>16 \mathrm{mg} / \mathrm{d}$ for male). $\beta$ was calculated by setting the G1 as reference. Significantly associations were denoted with bold.

\section{Discussion}

To the best of our knowledge, this is the first study to investigate cross-sectional associations between dietary nicotinamide intake and patient-reported outcomes, i.e., fatigue, anxiety, depression, emotional and cognitive functioning, and hand-grip strength in CRC survivors. Our findings indicate that a higher intake of nicotinamide, the main dietary $\mathrm{NAD}^{+}$precursor, was significantly associated with lower levels of self-reported fatigue and anxiety in CRC survivors 2-10 years post-diagnosis in analyses adjusted for age, sex, BMI, daily average energy, number of comorbidities, received chemotherapy (yes/no), hours of per week MVPA, years since diagnosis, and supplement usage (yes/no). Dose-response associations were observed when modeling nicotinamide intake categorized into three groups based on different intake levels (low, optimal, and high) with fatigue and anxiety and depression. We did not observe significant associations with hand-grip strength or emotional or cognitive functioning after adjusting for relevant confounders.

Complaints of fatigue are frequently reported by CRC survivors [35]. According to current intervention guidelines on fatigue in cancer survivors, physical activity interventions have been found to counteract fatigue [36]. However, due to comorbidities or advanced age, some older adults may not have the required strength for intensive exercise, which may restrict the practical application of such interventions among CRC survivors. Compared to physical activity interventions, nutrition and other supplement interventions are generally tolerable and may have a wider application or may be included in physical intervention programs. Although underlying mechanisms remain elusive, it is generally believed that nutritional status may be an important factor of fatigue. There are only a limited number of human studies covering this field, most of which have found that Vitamin D supplementation and high levels of Vitamin B6 status may be beneficial to alleviate fatigue and other patient-reported outcomes [30,37,38], and in general adhering to specific dietary WCRF/AICR (World Cancer Research Fund and the American Institute for Cancer Research) recommendations is associated with better HRQoL and less fatigue in CRC survivors [39]. However, most evidence for an association between dietary components and fatigue has been derived from studies with patients suffering from chronic fatigue syndrome (CFS). In these studies, nutritional deficiencies of Vitamin C, Vitamin B, sodium, magnesium, zinc, folic acid, L-carnitine, L-tryptophan, essential fatty acids, and co-enzyme 
Q10 have been reported in CFS subjects [40,41]. As for depression, stress, and anxiety syndromes, earlier studies have mostly been targeted on the general populations instead of CRC survivors. Dietary B vitamins intake was found to be associated with decreased prevalence of depression, anxiety, and stress syndromes [42,43]. More specifically, higher intakes of vitamin B6 [44], folate [44,45], B12 [46], and biotin [47] were negatively associated with psychological distress. Our findings add to the findings of these reports that documented the association between dietary vitamin B intake and distress, since nicotinamide is one of the forms of vitamin B3.

As an essential micronutrient, nicotinamide is also serving as one of the $\mathrm{NAD}^{+}$generating dietary precursors [8]. Supplementing $\mathrm{NAD}^{+}$generating precursors has been found effective in animal studies to counteract oxidative stress and chronic inflammation, which are associated with aging and aging-related diseases. Nicotinamide supplementation reduced oxidative stress and inflammation in high-fat diet obese mice [48]; nicotinamide mononucleotide supplementation reversed vascular dysfunction, reduced oxidative stress, and restored SIRT 1 activity in aging mice [49]; and nicotinamide riboside was found to protect against ROS to extend lifespan in C. elegans [50]. However, in our study, no association between nicotinamide intake and protein carbonyl content was observed. Except for a recent randomized controlled trial combining nicotinamide adenine dinucleotide (NADH) and co-enzyme Q10 that reduced fatigue in CFS patients [51], so far, evidence on NAD ${ }^{+}$ targeting interventions against patient-reported outcomes is scarce. More translational research is needed to bridge the gap between animal studies and human populations. Additionally, it is still under debate whether inflammation and oxidative stress are the underlying mechanisms that lead to fatigue and mental complaints. Emerging evidence is also inconsistent, and there are only a few studies involving cancer survivors. Some cross-sectional studies have found associations between certain cytokines, oxidative stress markers (e.g., protein carbonyl contents, lipid peroxidation markers), and fatigue or depression $[18,19,41]$, while another study did not [40]. Recently, an observational study suggested that $45 \%$ of the association between adhering to the WCRF dietary lifestyle score and fatigue was mediated by inflammatory markers [52]. Our study did not observe significant associations between protein carbonyl contents and patient-reported outcomes, which may be due to the relatively long years of survival (up to 2-10 years) of participants. In these survivors, the anti-oxidative system may already have been activated to counteract the stress, or this may be due to the relatively small sample size. The degradation of samples over long storage time (8 years) may also have had an effect on serum protein carbonyl contents. We did not find any significant association between nicotinamide intake and hand-grip strength, which is an indicator of muscle strength. This maybe also due to the small sample size of our study, or that other $\mathrm{NAD}^{+}$generating precursors, e.g., nicotinamide riboside may be more relevant in terms of maintaining muscle strength.

Recent study has demonstrated that most tissues rely on nicotinamide for $\mathrm{NAD}^{+}$ synthesis [53]. From our data, we did not find any association between nicotinamide intake and serum $\mathrm{NAD}^{+}$levels. In other words, a higher level of nicotinamide intake was not correlated with higher serum $\mathrm{NAD}^{+}$levels. However, the serum $\mathrm{NAD}^{+}$levels we measured were lower than those reported recently [54]. This difference may be the result of the long period storage of the serum in our study (8 years) versus the other study (half a year) [54]. We included "sample storage time" as a covariate into the final regression model, and yet no association between $\mathrm{NAD}^{+}$levels and outcomes was observed, which indicates that when investigating the relation between $\mathrm{NAD}^{+}$-status and physical and mental outcomes of cancer survivors, serum samples should be used that are stored for a shorter period.

Currently, no specific guidelines are available indicating which nicotinamide intake levels are suggested among CRC survivors. Thus, even though according to our findings, a higher level of nicotinamide intake seems to be beneficial, CRC survivors are advised to follow dietary guidelines for general populations (i.e., for adult women without pregnancy nor breastfeeding and men, 14 and $16 \mathrm{mg} / \mathrm{d}$, respectively). However, we doubt whether this may be sufficient to counteract an increased activity of $\mathrm{NAD}^{+}$-degrading enzymes, 
for instance poly (ADP-ribose) polymerase 1 (PARP1) and CD38, due to inflammatory conditions induced by cancer cell metabolism itself as well as by treatment [55-57]. In this study, almost $50 \%$ of the female CRC survivors did not meet the Dutch RDA level $(13 \mathrm{mg} / \mathrm{d})$ [16]. Therefore, it is advised to include an assessment of nicotinamide intake in dietary assessments and interventions for cancer survivors.

One of the strengths of our study is that we selected a relatively rigorous criterion to adjust for potential confounders, considering factors such as MVPA levels, energy intake, and intake of supplements, which allowed for a comprehensive understanding of associations between nicotinamide intake and patient-reported outcomes. However, some limitations must also be considered. First, similar to other cross-sectional studies, we cannot draw conclusions about causality. Participants reporting higher levels of fatigue and anxiety might have a poorer appetite or fail to follow an adequate and balanced diet, which may lead to a lower level of nicotinamide intake. However, after adjusting for daily total energy intake and the use of supplements, the associations we observed remained significant and unchanged. In addition, we calculated nicotinamide intake only, without considering the contribution from dietary L-tryptophan that is used for de novo $\mathrm{NAD}^{+}$synthesis. Although it is generally assumed that $60 \mathrm{mg}$ of tryptophan is equivalent to $1 \mathrm{mg}$ of nicotinamide [58], the tryptophan intake of CRC survivors is not known. Based on intake data from a recent study including 40 Dutch hemodialysis patients, it is considered likely that the tryptophan intake of Dutch adults is meeting the requirements, since this study reported a mean dietary tryptophan intake of $909 \pm 235 \mathrm{mg} / \mathrm{d}$ [59]. NAD ${ }^{+}$can be synthesized from tryptophan by the kynurenine pathway [60], and it can be speculated that a low dietary intake of nicotinamide may lead to an increased production of $\mathrm{NAD}^{+}$, which may lead to the accumulation of metabolites produced by the kynurenine pathway. Recently, plasma kynurenine metabolites were found to possibly mediate an inflammation-associated depressive symptom profile in patients with depression syndromes [61]. Secondly, the cross-sectional design with a relatively limited sample size does prohibit a definitive or causal conclusion about nicotinamide intake and patient-reported outcomes. Further prospective follow-up and intervention studies that include a reliable estimation of $\mathrm{NAD}^{+}$ status are warranted to corroborate these findings.

\section{Conclusions}

In conclusion, our findings indicate that a higher intake of dietary nicotinamide is inversely associated with fatigue and anxiety symptoms reported by long-term CRC survivors, 2 to 10 years post-diagnosis. CRC survivors and health care professionals should be aware that having a balanced diet is of importance with respect to a sufficient nicotinamide intake. Further prospective and intervention studies are warranted to have a better understanding on the potential beneficial effects of nicotinamide and other $\mathrm{NAD}^{+}$ precursors on patient-reported outcomes such as fatigue, depression, and anxiety.

Supplementary Materials: The following are available online at https:/ /www.mdpi.com/article/ 10.3390/nu13113707/s1, Table S1: Associations of serum NAD+ levels with hand-grip strength, emotional and cognitive functioning, fatigue, anxiety, and depression. Table S2: Associations of serum protein carbonyl contents with hand-grip strength, emotional and cognitive functioning, fatigue, anxiety, and depression. Table S3: Dose-response relationships between daily nicotinamide intake and hand-grip strength, emotional and cognitive functioning, fatigue, anxiety, and depression.

Author Contributions: All authors have substantially contributed to the study and manuscript design, data analyses, data interpretation, and/or revision and have approved this final version of the work. The authors have agreed to take accountability for all aspects of this study. The authors' responsibilities were as follows: W.W., G.J.H., M.J.L.B. and M.P.W. designed and conducted the research; W.W. and G.J.H. conducted the laboratory analyses; W.W., G.J.H., M.J.L.B. and M.P.W. analyzed the data and performed the statistical analyses; W.W., G.J.H., M.J.L.B. and M.P.W. wrote the manuscript and had primary responsibility for the final content; W.W., G.J.H., M.J.L.B., A.K., M.-F.K., S.J.P.M.E., S.O.B., F.-J.v.S. and M.P.W. revised and edited the manuscript. All authors have read and agreed to the published version of the manuscript. 
Funding: The EnCoRe study was supported by Kankeronderzoekfonds Limburg as part of the Health Foundation Limburg (grant 00005739), by Stichting Alpe d'Huzes within the research program "Leven met kanker" of the Dutch Cancer Society grants UM 2010-4867 and UM 2012-5653, and by ERA-NET on Translational Cancer Research (TRANSCAN: Dutch Cancer Society (UM 2014-6877)). M. Kenkhuis is supported by a grant from Wereld KankerOnderzoek Fonds (WKOF)/World Cancer Research Fund International (WCRF) (grant number 2017/1619). W.Wu is supported by China Scholarship Council (CSC) (grant number 201806160187).

Institutional Review Board Statement: The study was conducted according to the guidelines of the Declaration of Helsinki and approved by the Medical Ethics Committee of the Academic Hospital Maastricht and Maastricht University, The Netherlands.

Informed Consent Statement: Informed consent was obtained from all subjects involved in the study.

Data Availability Statement: Data described in the manuscript, code book, and analytic code will be made available upon request pending (e.g., application and approval, payment, other). Requests for data of the EnCoRe study can be sent to Martijn Bours, Department of Epidemiology, GROWSchool for Oncology and Developmental Biology, Maastricht University, The Netherlands (e-mail: m.bours@maastrichtuniversity.nl).

Acknowledgments: We would like to thank all participants of the EnCoRe study and the health professionals in the three hospitals involved in the recruitment of participants of the study: Maastricht University Medical Centre+, VieCuriMedical Centre, and Zuyderland Medical Centre. We would also like to thank the MEMIC centre for data and information management for facilitating the logistic processes and data management of our study. Finally, we would like to thank the research dietitians and research assistant who are responsible for patient inclusion and follow-up, performing home visits, as well as data collection and processing.

Conflicts of Interest: The authors declare that they have no conflict of interest.

\section{References}

1. Kuipers, E.J.; Grady, W.M.; Lieberman, D.; Seufferlein, T.; Sung, J.J.; Boelens, P.G.; van de Velde, C.J.H.; Watanabe, T. Colorectal cancer. Nat. Rev. Dis. Primer 2015, 1, 15065. [CrossRef]

2. Arnold, M.; Sierra, M.S.; Laversanne, M.; Soerjomataram, I.; Jemal, A.; Bray, F. Global Patterns and Trends in Colorectal Cancer Incidence and Mortality. Gut 2017, 66, 683-691. [CrossRef]

3. Jess, T.; Rungoe, C.; Peyrin-Biroulet, L. Risk of Colorectal Cancer in Patients with Ulcerative Colitis: A Meta-Analysis of Population-Based Cohort Studies. Clin. Gastroenterol. Hepatol. Off. Clin. Pract. J. Am. Gastroenterol. Assoc. 2012, 10, 639-645. [CrossRef]

4. $\quad$ El-Shami, K.; Oeffinger, K.C.; Erb, N.L.; Willis, A.; Bretsch, J.K.; Pratt-Chapman, M.L.; Cannady, R.S.; Wong, S.L.; Rose, J.; Barbour, A.L.; et al. American Cancer Society Colorectal Cancer Survivorship Care Guidelines. CA Cancer J. Clin. 2015, 65, 428-455. [CrossRef] [PubMed]

5. Buccafusca, G.; Proserpio, I.; Tralongo, A.C.; Rametta Giuliano, S.; Tralongo, P. Early Colorectal Cancer: Diagnosis, Treatment and Survivorship Care. Crit. Rev. Oncol. Hematol. 2019, 136, 20-30. [CrossRef] [PubMed]

6. Chini, C.C.S.; Tarragó, M.G.; Chini, E.N. Nad and the aging process: Role in life, death and everything in between. Mol. Cell. Endocrinol. 2017, 455, 62-74. [CrossRef] [PubMed]

7. Verdin, E. NAD ${ }^{+}$in Aging, Metabolism, and Neurodegeneration. Science 2015, 350, 1208-1213. [CrossRef] [PubMed]

8. Braidy, N.; Berg, J.; Clement, J.; Khorshidi, F.; Poljak, A.; Jayasena, T.; Grant, R.; Sachdev, P. Role of Nicotinamide Adenine Dinucleotide and Related Precursors as Therapeutic Targets for Age-Related Degenerative Diseases: Rationale, Biochemistry, Pharmacokinetics, and Outcomes. Antioxid. Redox Signal. 2019, 30, 251-294. [CrossRef] [PubMed]

9. Clement, J.; Wong, M.; Poljak, A.; Sachdev, P.; Braidy, N. The Plasma NAD+ Metabolome Is Dysregulated in "Normal” Aging. Rejuvenation Res. 2019, 22, 121-130. [CrossRef]

10. Abele, F.; Höfer, K.; Bernhard, P.; Grawenhoff, J.; Seidel, M.; Krause, A.; Kopf, S.; Schröter, M.; Jäschke, A. A Novel NAD-RNA Decapping Pathway Discovered by Synthetic Light-Up NAD-RNAs. Biomolecules 2020, 10, 513. [CrossRef]

11. Fletcher, R.S.; Ratajczak, J.; Doig, C.L.; Oakey, L.A.; Callingham, R.; Da Silva Xavier, G.; Garten, A.; Elhassan, Y.S.; Redpath, P.; Migaud, M.E.; et al. Nicotinamide Riboside Kinases Display Redundancy in Mediating Nicotinamide Mononucleotide and Nicotinamide Riboside Metabolism in Skeletal Muscle Cells. Mol. Metab. 2017, 6, 819-832. [CrossRef]

12. Alegre, J.; Rosés, J.M.; Javierre, C.; Ruiz-Baqués, A.; Segundo, M.J.; Fernández de Sevilla, T. Nicotinamida Adenina Dinucleótido (NADH) En Pacientes Con Síndrome de Fatiga Crónica. Rev. Clin. Esp. 2010, 210, 284-288. [CrossRef] [PubMed]

13. Mitchell, S.J.; Bernier, M.; Aon, M.A.; Cortassa, S.; Kim, E.Y.; Fang, E.F.; Palacios, H.H.; Ali, A.; Navas-Enamorado, I.; Di Francesco, A.; et al. Nicotinamide Improves Aspects of Healthspan, but Not Lifespan, in Mice. Cell Metab. 2018, 27, 667-676.e4. [CrossRef] 
14. Pirinen, E.; Auranen, M.; Khan, N.A.; Brilhante, V.; Urho, N.; Pessia, A.; Hakkarainen, A.; Kuula, J.; Heinonen, U.; Schmidt, M.S.; et al. Niacin Cures Systemic NAD+ Deficiency and Improves Muscle Performance in Adult-Onset Mitochondrial Myopathy. Cell Metab. 2020, 31, 1078-1090.e5. [CrossRef] [PubMed]

15. Wang, S.; Prizment, A.; Thyagarajan, B.; Blaes, A. Cancer Treatment-Induced Accelerated Aging in Cancer Survivors: Biology and Assessment. Cancers 2021, 13, 427. [CrossRef] [PubMed]

16. McHugh, D.; Gil, J. Senescence and Aging: Causes, Consequences, and Therapeutic Avenues. J. Cell Biol. 2018, 217, 65-77. [CrossRef] [PubMed]

17. The Habitual Micronutrient Intake of Dutch Adults (VCP 2007-2010) Compared with Dietary Reference Values Set by the Health Council of The Netherlands (2014) and EFSA (2010-2017) (2018) RIVM. Available online: https:/ / www.rivm.nl/documenten/ habitual-micronutrient-intake-of-dutch-adults-vcp-2007-2010-compared-with-dietary (accessed on 8 July 2021).

18. Fletcher, M.A.; Zeng, X.R.; Barnes, Z.; Levis, S.; Klimas, N.G. Plasma Cytokines in Women with Chronic Fatigue Syndrome. J. Transl. Med. 2009, 7, 96. [CrossRef]

19. Margaritelis, N.V.; Veskoukis, A.S.; Paschalis, V.; Vrabas, I.S.; Dipla, K.; Zafeiridis, A.; Kyparos, A.; Nikolaidis, M.G. Blood Reflects Tissue Oxidative Stress: A Systematic Review. Biomarkers 2015, 20, 97-108. [CrossRef]

20. Van Roekel, E.H.; Bours, M.J.L.; Breedveld-Peters, J.J.L.; Meijer, K.; Kant, I.; Van Den Brandt, P.A.; Sanduleanu, S.; Beets, G.L.; Weijenberg, M.P. Light Physical Activity Is Associated with Quality of Life after Colorectal Cancer. Med. Sci. Sports Exerc. 2015, 47, 2493-2503. [CrossRef]

21. Koole, J.L.; Bours, M.J.L.; Breedveld-Peters, J.J.L.; van Roekel, E.H.; van Dongen, M.C.J.M.; Eussen, S.J.P.M.; van Zutphen, M.; van Duijnhoven, F.J.B.; Boshuizen, H.C.; Weijenberg, M.P. Evaluating the Validity of a Food Frequency Questionnaire in Comparison with a 7-Day Dietary Record for Measuring Dietary Intake in a Population of Survivors of Colorectal Cancer. J. Acad. Nutr. Diet. 2020, 120, 245-257. [CrossRef]

22. Koole, J.L.; Bours, M.J.L.; Breedveld-Peters, J.J.L.; van Roekel, E.H.; Breukink, S.O.; Janssen-Heijnen, M.L.G.; Vogelaar, F.J.; Aquarius, M.; Keulen, E.; Stoot, J.; et al. Is Dietary Supplement Use Longitudinally Associated with Fatigue in Stage I-III Colorectal Cancer Survivors? Clin. Nutr. 2020, 39, 234-241. [CrossRef]

23. Breedveld-Peters, J.J.L.; Koole, J.L.; Müller-Schulte, E.; van der Linden, B.W.A.; Windhausen, C.; Bours, M.J.L.; van Roekel, E.H.; Weijenberg, M.P. Colorectal Cancers Survivors' Adherence to Lifestyle Recommendations and Cross-Sectional Associations with Health-Related Quality of Life. Br. J. Nutr. 2018, 120, 188-197. [CrossRef]

24. Levine, R.L.; Garland, D.; Oliver, C.N.; Amici, A.; Climent, I.; Lenz, A.G.; Ahn, B.W.; Shaltiel, S.; Stadtman, E.R. Determination of Carbonyl Content in Oxidatively Modified Proteins. Methods Enzymol. 1990, 186, 464-478. [CrossRef] [PubMed]

25. Bernofsky, C.; Swan, M. An Improved Cycling Assay for Nicotinamide Adenine Dinucleotide. Anal. Biochem. 1973, 53, 452-458. [CrossRef]

26. Slocombe, L.L.; Colditz, I.G. A Rapid Colorimetric Assay for Measuring Low Concentrations of Haemoglobin in Large Numbers of Bovine Plasma Samples. Food Agric. Immunol. 2011, 22, 135-143. [CrossRef]

27. Peng, Z.; Xiang, W.; Zhou, J.; Cao, J.; Li, Z.; Gao, H.; Zhang, J.; Shen, H. Hemolytic Specimens in Complete Blood Cell Count: Red Cell Parameters Could Be Revised by Plasma Free Hemoglobin. J. Clin. Lab. Anal. 2020, 34, e23218. [CrossRef] [PubMed]

28. Kristiansen, J. The Guide to Expression of Uncertainty in Measurement Approach for Estimating Uncertainty: An Appraisal. Clin. Chem. 2003, 49, 1822-1829. [CrossRef]

29. Elands, R.J.J.; Simons, C.C.J.M.; van Dongen, M.; Schouten, L.J.; Verhage, B.A.J.; van den Brandt, P.A.; Weijenberg, M.P. A Systematic Literature Review and Meta-Regression Analysis on Early-Life Energy Restriction and Cancer Risk in Humans. PLoS ONE 2016, 11, e0158003. [CrossRef]

30. Koole, J.L.; Bours, M.J.L.; van Roekel, E.H.; Breedveld-Peters, J.J.L.; van Duijnhoven, F.J.B.; van den Ouweland, J.; Breukink, S.O.; Janssen-Heijnen, M.L.G.; Keulen, E.T.P.; Weijenberg, M.P. Higher Serum Vitamin D Concentrations Are Longitudinally Associated with Better Global Quality of Life and Less Fatigue in Colorectal Cancer Survivors up to 2 Years after Treatment. Cancer Epidemiol. Prev. Biomark. 2020, 29, 1135-1144. [CrossRef]

31. Van Roekel, E.H.; Bours, M.J.L.; Te Molder, M.E.M.; Breedveld-Peters, J.J.L.; Olde Damink, S.W.M.; Schouten, L.J.; Sanduleanu, S.; Beets, G.L.; Weijenberg, M.P. Associations of Adipose and Muscle Tissue Parameters at Colorectal Cancer Diagnosis with Long-Term Health-Related Quality of Life. Qual. Life Res. 2017, 26, 1745-1759. [CrossRef]

32. Van Roekel, E.H.; Winkler, E.A.H.; Bours, M.J.L.; Lynch, B.M.; Willems, P.J.B.; Meijer, K.; Kant, I.J.; Beets, G.L.; Sanduleanu, S.; Healy, G.N.; et al. Associations of Sedentary Time and Patterns of Sedentary Time Accumulation with Health-Related Quality of Life in Colorectal Cancer Survivors. Prev. Med. Rep. 2016, 4, 262-269. [CrossRef]

33. Ainsworth, B.E.; Haskell, W.L.; Leon, A.S.; Jacobs, D.R.; Montoye, H.J.; Sallis, J.F.; Paffenbarger, R.S. Compendium of Physical Activities: Classification of Energy Costs of Human Physical Activities. Med. Sci. Sports Exerc. 1993, 25, 71-80. [CrossRef]

34. Office of Dietary Supplements-Niacin. Available online: https://ods.od.nih.gov/factsheets/Niacin-HealthProfessional/ (accessed on 21 October 2020).

35. Thong, M.S.Y.; Mols, F.; Wang, X.S.; Lemmens, V.E.P.P.; Smilde, T.J.; van de Poll-Franse, L.V. Quantifying Fatigue in (Long-Term) Colorectal Cancer Survivors: A Study from the Population-Based Patient Reported Outcomes Following Initial treatment and Long term Evaluation of Survivorship registry. Eur. J. Cancer Oxf. Engl. 2013, 49, 1957-1966. [CrossRef] 
36. Bower, J.E.; Bak, K.; Berger, A.; Breitbart, W.; Escalante, C.P.; Ganz, P.A.; Schnipper, H.H.; Lacchetti, C.; Ligibel, J.A.; Lyman, G.H.; et al. Screening, Assessment, and Management of Fatigue in Adult Survivors of Cancer: An American Society of Clinical Oncology Clinical Practice Guideline Adaptation. J. Clin. Oncol. 2014, 32, 1840-1850. [CrossRef] [PubMed]

37. Bours, M.J.; Beijer, S.; Winkels, R.M.; van Duijnhoven, F.J.; Mols, F.; Breedveld-Peters, J.J.; Kampman, E.; Weijenberg, M.P.; van de Poll-Franse, L.V. Dietary Changes and Dietary Supplement Use, and Underlying Motives for These Habits Reported by Colorectal Cancer Survivors of the Patient Reported Outcomes Following Initial Treatment and Long-Term Evaluation of Survivorship (PROFILES) Registry. Br. J. Nutr. 2015, 114, 286-296. [CrossRef] [PubMed]

38. Koole, J.L.; Bours, M.J.L.; Geijsen, A.J.M.R.; Gigic, B.; Ulvik, A.; Kok, D.E.; Brezina, S.; Ose, J.; Baierl, A.; Böhm, J.; et al. Circulating B-Vitamin Biomarkers and B-Vitamin Supplement Use in Relation to Quality of Life in Patients with Colorectal Cancer: Results from the FOCUS Consortium. Am. J. Clin. Nutr. 2021, 113, 1468-1481. [CrossRef] [PubMed]

39. Kenkhuis, M.-F.; van der Linden, B.W.A.; Breedveld-Peters, J.J.L.; Koole, J.L.; van Roekel, E.H.; Breukink, S.O.; Mols, F.; Weijenberg, M.P.; Bours, M.J.L. Associations of the Dietary World Cancer Research Fund/American Institute for Cancer Research (WCRF/AICR) Recommendations with Patient-Reported Outcomes in Colorectal Cancer Survivors 2-10 Years Post-Diagnosis: A Cross-Sectional Analysis. Br. J. Nutr. 2021, 125, 1188-1200. [CrossRef] [PubMed]

40. Azzolino, D.; Arosio, B.; Marzetti, E.; Calvani, R.; Cesari, M. Nutritional Status as a Mediator of Fatigue and Its Underlying Mechanisms in Older People. Nutrients 2020, 12, 444. [CrossRef]

41. Bjørklund, G.; Dadar, M.; Pen, J.J.; Chirumbolo, S.; Aaseth, J. Chronic Fatigue Syndrome (CFS): Suggestions for a Nutritional Treatment in the Therapeutic Approach. Biomed. Pharmacother. 2019, 109, 1000-1007. [CrossRef]

42. Herbison, C.E.; Hickling, S.; Allen, K.L.; O'Sullivan, T.A.; Robinson, M.; Bremner, A.P.; Huang, R.-C.; Beilin, L.J.; Mori, T.A.; Oddy, W.H. Low Intake of B-Vitamins Is Associated with Poor Adolescent Mental Health and Behaviour. Prev. Med. 2012, 55, 634-638. [CrossRef]

43. Kennedy, D.O.; Veasey, R.; Watson, A.; Dodd, F.; Jones, E.; Maggini, S.; Haskell, C.F. Effects of High-Dose B Vitamin Complex with Vitamin C and Minerals on Subjective Mood and Performance in Healthy Males. Psychopharmacology 2010, 211, 55-68. [CrossRef] [PubMed]

44. Murakami, K.; Miyake, Y.; Sasaki, S.; Tanaka, K.; Arakawa, M. Dietary Folate, Riboflavin, Vitamin B-6, and Vitamin B-12 and Depressive Symptoms in Early Adolescence: The Ryukyus Child Health Study. Psychosom. Med. 2010, 72, 763-768. [CrossRef]

45. Murakami, K.; Mizoue, T.; Sasaki, S.; Ohta, M.; Sato, M.; Matsushita, Y.; Mishima, N. Dietary Intake of Folate, Other B Vitamins, and $\omega-3$ Polyunsaturated Fatty Acids in Relation to Depressive Symptoms in Japanese Adults. Nutrition 2008, 24, 140-147. [CrossRef]

46. Mishra, G.D.; McNaughton, S.A.; O'Connell, M.A.; Prynne, C.J.; Kuh, D. Intake of B Vitamins in Childhood and Adult Life in Relation to Psychological Distress among Women in a British Birth Cohort. Public Health Nutr. 2009, 12, 166-174. [CrossRef] [PubMed]

47. Mahdavifar, B.; Hosseinzadeh, M.; Salehi-Abargouei, A.; Mirzaei, M.; Vafa, M. Dietary Intake of B Vitamins and Their Association with Depression, Anxiety, and Stress Symptoms: A Cross-Sectional, Population-Based Survey. J. Affect. Disord. 2021, 288, 92-98. [CrossRef] [PubMed]

48. Gilmour, B.C.; Gudmundsrud, R.; Frank, J.; Hov, A.; Lautrup, S.; Aman, Y.; Røsjø, H.; Brenner, C.; Ziegler, M.; Tysnes, O.-B.; et al. Targeting NAD+ in Translational Research to Relieve Diseases and Conditions of Metabolic Stress and Ageing. Mech. Ageing Dev. 2020, 186, 111208. [CrossRef] [PubMed]

49. De Picciotto, N.E.; Gano, L.B.; Johnson, L.C.; Martens, C.R.; Sindler, A.L.; Mills, K.F.; Imai, S.; Seals, D.R. Nicotinamide Mononucleotide Supplementation Reverses Vascular Dysfunction and Oxidative Stress with Aging in Mice. Aging Cell 2016, 15, 522-530. [CrossRef]

50. Mouchiroud, L.; Houtkooper, R.H.; Moullan, N.; Katsyuba, E.; Ryu, D.; Cantó, C.; Mottis, A.; Jo, Y.-S.; Viswanathan, M.; Schoonjans, K.; et al. The NAD+/Sirtuin Pathway Modulates Longevity through Activation of Mitochondrial UPR and FOXO Signaling. Cell 2013, 154, 430-441. [CrossRef]

51. Castro-Marrero, J.; Sáez-Francàs, N.; Segundo, M.J.; Calvo, N.; Faro, M.; Aliste, L.; Fernández de Sevilla, T.; Alegre, J. Effect of Coenzyme Q10 plus Nicotinamide Adenine Dinucleotide Supplementation on Maximum Heart Rate after Exercise Testing in Chronic Fatigue Syndrome-A Randomized, Controlled, Double-Blind Trial. Clin. Nutr. 2016, 35, 826-834. [CrossRef] [PubMed]

52. Wesselink, E.; van Baar, H.; van Zutphen, M.; Tibosch, M.; Kouwenhoven, E.A.; Keulen, E.T.P.; Kok, D.E.; van Halteren, H.K.; Breukink, S.O.; de Wilt, J.H.W.; et al. Inflammation Is a Mediating Factor in the Association between Lifestyle and Fatigue in Colorectal Cancer Patients. Cancers 2020, 12, 3701. [CrossRef]

53. Liu, L.; Su, X.; Quinn, W.J.; Hui, S.; Krukenberg, K.; Frederick, D.W.; Redpath, P.; Zhan, L.; Chellappa, K.; White, E.; et al. Quantitative Analysis of NAD Synthesis-Breakdown Fluxes. Cell Metab. 2018, 27, 1067-1080.e5. [CrossRef] [PubMed]

54. Braidy, N.; Lim, C.K.; Grant, R.; Brew, B.J.; Guillemin, G.J. Serum Nicotinamide Adenine Dinucleotide Levels through Disease Course in Multiple Sclerosis. Brain Res. 2013, 1537, 267-272. [CrossRef] [PubMed]

55. Salech, F.; Ponce, D.P.; Paula-Lima, A.C.; SanMartin, C.D.; Behrens, M.I. Nicotinamide, a Poly ADP-Ribose Polymerase 1 (PARP-1) Inhibitor, as an Adjunctive Therapy for the Treatment of Alzheimer's Disease. Front. Aging Neurosci. 2020, 12, 255. [CrossRef] [PubMed]

56. Matulonis, U.A.; Monk, B.J. PARP Inhibitor and Chemotherapy Combination Trials for the Treatment of Advanced Malignancies: Does a Development Pathway Forward Exist? Ann. Oncol. Off. J. Eur. Soc. Med. Oncol. 2017, 28, 443-447. [CrossRef] 
57. Sachdev, E.; Tabatabai, R.; Roy, V.; Rimel, B.J.; Mita, M.M. PARP Inhibition in Cancer: An Update on Clinical Development. Target. Oncol. 2019, 14, 657-679. [CrossRef] [PubMed]

58. Fukuwatari, T.; Shibata, K. Nutritional Aspect of Tryptophan Metabolism. Int. J. Tryptophan Res. 2013, 6, 3-8. [CrossRef]

59. Post, A.; Huberts, M.; Poppe, E.; van Faassen, M.; Kema, I.P.; Vogels, S.; Geleijnse, J.M.; Westerhuis, R.; Ipema, K.J.R.; Bakker, S.J.L.; et al. Tryptophan Intake and Tryptophan Losses in Hemodialysis Patients: A Balance Study. Nutrients 2019, 11, 2851. [CrossRef]

60. Badawy, A.A.-B. Kynurenine Pathway of Tryptophan Metabolism: Regulatory and Functional Aspects. Int. J. Tryptophan Res. 2017, 10, 1178646917691938. [CrossRef]

61. Haroon, E.; Welle, J.R.; Woolwine, B.J.; Goldsmith, D.R.; Baer, W.; Patel, T.; Felger, J.C.; Miller, A.H. Associations among Peripheral and Central Kynurenine Pathway Metabolites and Inflammation in Depression. Neuropsychopharmacology 2020, 45, $998-1007$. [CrossRef] 